\title{
$D C D C 2$ Polymorphism Is Associated with Left Temporoparietal Gray and White Matter Structures during Development
}

\author{
Fahimeh Darki, ${ }^{1}$ Myriam Peyrard-Janvid, ${ }^{2}$ Hans Matsson, ${ }^{2}$ Juha Kere,,${ }^{2,3,4}$ and Torkel Klingberg ${ }^{1}$ \\ ${ }^{1}$ Department of Neuroscience, Karolinska Institutet, 17177 Solna, Sweden, ${ }^{2}$ Department of Biosciences and Nutrition, Karolinska Institutet, 14183 \\ Huddinge, Sweden, ${ }^{3}$ Science for Life Laboratory, Karolinska Institutet, 17177 Solna, Sweden, and ${ }^{4}$ Research Programs Unit, Haartman Institute, University \\ of Helsinki, and Folkhälsan Institute of Genetics, 00014 Helsinki, Finland
}

\begin{abstract}
Three genes, DYX1C1, DCDC2, and KIAA0319, have been previously associated with dyslexia, neuronal migration, and ciliary function. Three polymorphisms within these genes, rs3743204 (DYX1C1), rs793842 (DCDC2), and rs6935076 (KIAA0319) have also been linked to normal variability of left temporoparietal white matter volume connecting the middle temporal cortex to the angular and supramarginal gyri. Here, we assessed whether these polymorphisms are also related to the cortical thickness of the associated regions during childhood development using a longitudinal dataset of 76 randomly selected children and young adults who were scanned up to three times each, 2 years apart. rs793842 in DCDC2 was significantly associated with the thickness of left angular and supramarginal gyri as well as the left lateral occipital cortex. The cortex was significantly thicker for T-allele carriers, who also had lower white matter volume and lower reading comprehension scores. There was a negative correlation between white matter volume and cortical thickness, but only white matter volume predicted reading comprehension 2 years after scanning. These results show how normal variability in reading comprehension is related to gene, white matter volume, and cortical thickness in the inferior parietal lobe. Possibly, the variability of gray and white matter structures could both be related to the role of $D C D C 2$ in ciliary function, which affects both neuronal migration and axonal outgrowth.
\end{abstract}

Key words: ciliary function; developmental dyslexia; neuroimaging; reading ability; single nucleotide polymorphism; SNP; supramarginal and angular gyrus

\section{Introduction}

Developmental dyslexia, or reading disability, is one of the most common learning disorders among children (Shaywitz et al., 1990; Katusic et al., 2001). A different pattern of activation in the left temporoparietal, inferior parietal, and occipitotemporal cortical regions has been observed in impaired compared with normal readers (Shaywitz et al., 2002, 2004; Richlan et al., 2011; Richlan, 2012). Dyslexia has also been associated with structural deviations of gray and white matter in corresponding regions (Klingberg et al., 2000; Deutsch et al., 2005; Silani et al., 2005; Vinckenbosch et al., 2005; Niogi and McCandliss, 2006; Kron-

\footnotetext{
Received March 26, 2014; revised Aug. 26, 2014; accepted Sept. 16, 2014.

Author contributions: F.D., J.K., and T.K. designed research; F.D. performed research; F.D., M.P.-J., and H.M. analyzed data; F.D., M.P.-J., H.M., J.K., and T.K. wrote the paper.

This work was supported by the Knut and Alice Wallenberg Foundation, The Swedish Research Council, and a Swedish Royal Bank Tercentennial Foundation grant in the program "Learning and Memory in Children and Young Adults" to J.K. and T.K. We thank Jens Gisselgård, Ylva Samuelsson, Douglas Sjöwall, Iroise Dumontheil, Benjamin Garzon, Stina Söderqvist, and Sissela Bergman Nutley for help with the study administration; Kerstin Eriksson and Tomas Jonsson for the scanning of the participants; and Kristiina Tammimies, Ingegerd Fransson, and the Mutation Analysis Core Facility for genotyping.

The authors declare no competing financial interests.

Correspondence should be addressed to Torkel Klingberg, Karolinska Institutet, Retzius Väg 8, 17177 Stockholm, Sweden. E-mail: torkel.klingberg@ki.se.

DOI:10.1523/JNEUROSCI.1216-14.2014

Copyright $\odot 2014$ the authors $\quad 0270-6474 / 14 / 3414455-08 \$ 15.00 / 0$
}

bichler et al., 2008; Altarelli et al., 2013). These differences could rather be seen as the end distribution of a continuum in the general population, without any diagnosis of dyslexia (Klingberg et al., 2000; Nagy et al., 2004; Beaulieu et al., 2005; Deutsch et al., 2005; Niogi and McCandliss, 2006; Darki et al., 2012).

A small number of candidate genes, such as DYX1C1, DCDC2, and KIAA0319, have been associated with increased risk for reading impairment (Taipale et al., 2003; Cope et al., 2005; Meng et al., 2005; Schumacher et al., 2006; Eicher et al., 2014) as well as with neuronal migration during cortical development (Wang et al., 2006; Gabel et al., 2010; Peschansky et al., 2010; Szalkowski et al., 2012). At the cellular level, DYX1C1 and DCDC2 have been implicated in regulating ciliary growth and function (Massinen et al., 2011; Chandrasekar et al., 2013). Impaired ciliary function may lead to misplacement of neurons in the cerebral cortex and may hinder the axonal outgrowth (Higginbotham et al., 2012). Thus, genetic polymorphisms associated with ciliar functioning may lead to disturbances in both white and gray matter in the brain.

Gray matter volume alterations in association with single nucleotide polymorphisms (SNPs) in or near the DYX1C1, DCDC2, and KIAA0319 genes have been reported in some genetic imaging assessments (Meda et al., 2008; Jamadar et al., 2011). Functional MRI studies have also detected an association of genetic variants 
in KIAA0319 and DCDC2 with brain activation in superior temporal sulcus, as well as the left anterior inferior parietal and right temporal gyrus and lateral occipital cortex (LOC; Cope et al., 2012; Pinel et al., 2012).

Three SNPs, rs3743204 (DYX1C1), rs793842 (DCDC2), and rs6935076 (KIAA0319), showed significant effects on the normal variability of white matter volume in left temporoparietal regions in which the white matter pathways connect the middle temporal gyrus (MTG) to the angular gyrus (AG) and the supramarginal gyrus (SMG; Darki et al., 2012). These cortical regions have been reported to be functionally and structurally different in individuals in whom dyslexia has been diagnosed compared with normal readers (Paulesu et al., 2001; McCandliss et al., 2003; Carreiras et al., 2009).

Knowing the involvement of the dyslexia susceptibility genes DYX1C1, DCDC2, and KIAA0319 in neuronal migration and ciliary function, we aimed to assess whether the individual genotypes of the SNPs rs3743204, rs793842, and rs6935076 have any significant effect on the normal variability of cortical thickness in the temporal and parietal associated regions during development.

\section{Materials and Methods}

\section{Participants}

Seventy-six typically developing children and young adults, already included in our previous study (Darki et al., 2012), were scanned for the third time as a part of a longitudinal study (Söderqvist et al., 2010). The participants ( 41 males and 35 females) were in nine different age groups $(6,8,10,12,14,16,18,20$, and 25 years of age) with no reports of any neurological or psychological disorders. This study was approved by the ethics committee of the Karolinska University Hospital. Informed consent was provided by the participants or the parents of children $<18$ years of age.

\section{Genotyping}

Thirteen SNPs located in or in close vicinity to three dyslexia susceptibility genes (DYX1C1: rs3743204, rs3743205, and rs17819126; DCDC2: rs793842, rs793862, rs807701, rs2328819 rs2792682, rs7751169, and rs9460974; KIAA0319: rs4504469, rs6935076, and rs2143340) were genotyped with matrix-assisted laser desorption/ionization-time-of-flight mass spectrometry with iPLEX Gold assays, as previously described (Darki et al., 2012).

We previously (Darki et al., 2012) reported that three of these SNPs, rs3743204 (DYX1C1), rs793842 (DCDC2), and rs6935076 (KIAA0319) showed significant effects on the normal variability of white matter volume for two imaging rounds (i.e., the first two time points of the longitudinal dataset). Here, we analyzed the structural MRI data from all three time points to investigate the association of these SNPs with white matter structure and the cortical thickness. The association between these SNPs and behavior measures was also assessed.

\section{Behavioral assessment}

All subjects were assessed with a reading comprehension task using narrative and expository texts from the Progress in International Reading literacy Trend Study (PIRLS $2001 \mathrm{~T}$ ) and The International Association for the Evaluation of Educational Achievement Reading Literacy Study 1991. Reading comprehension tests included 77 items for four age groups including individuals ranging in age from 8 to 25 years and were administered either individually or in groups of 2-20 participants in a classroom (Söderqvist et al., 2010). Different age groups thus received different, but overlapping, sets of items. An item response theory analysis (Bond and Fox, 2003) was then used to achieve a reading ability $z$-score for each subject, which was used for further analysis.

Additionally, a word decoding task called "word chains" was tested. This is similar to the English Woodcock Johnson Word-ID test, in which the subjects had 72 sets of written words, each consisting of three words without spaces in between. The task was to read as many words as possible during 2 min and mark with a pencil where the spaces should occur.
The score is based on the number of words that has been marked correctly (Woodcock, 1987).

\section{Structural brain imaging and analysis}

T1-weighted spin echo scans were collected with a $1.5 \mathrm{~T}$ Avanto scanner (Siemens Medical System) using a 3D magnetization-prepared rapid acquisition gradient echo sequence with $\mathrm{TR}=2300 \mathrm{~ms}$, TE $=2.92 \mathrm{~ms}$, $256 \times 256$ matrix size, 176 sagittal slices, and $1 \mathrm{~mm}^{3}$ isotropic voxel size.

Voxel-based morphometry, which segmented the brain into gray matter, white matter, and CSF, was performed on structural data collected across all three rounds of data collection using SPM5, Diffeomorphic Anatomical Registration Through Exponentiated Lie Algebra (DARTEL) toolbox (Ashburner, 2007). The structural data of all individuals were first segmented into gray matter, white matter, and CSF using a mixturemodel cluster analysis, which identifies the voxels by matching their intensities to the tissue types and combines this information with a priori knowledge from probability maps of these three tissues. Next, the tissuesegmented images were iteratively registered to each other to create a template. Then the images were subjected to a nonlinear modulation by multiplying the registered images with the Jacobian determinants. The modulation reflects the probability of being locally expanded or contracted to fit to the template. The modulated white matter segmented images were registered to Montreal Neurological Institute (MNI) space by affine transformation and then smoothed with an $8 \mathrm{~mm}$ Gaussian kernel for further statistical analysis.

\section{SNP genotypes and white matter volume}

All white matter segmented images were analyzed by second-level SPM analysis, using a flexible factorial design in SPM8, to assess the variation of white matter volume with respect to genotype variability. Flexible factorial design allowed specifying the participants and it considered the repeated measures for all individuals by including subjects and testing rounds as factors. The SNPs rs3743204 (DYX1C1), rs793842 (DCDC2), and rs6935076 (KIAA0319) were entered separately as a main factor in the model. The sample sizes by genotype are as follows: rs3743204 (GG, $n=53$; GT/TT, $n=23$ ); rs793842 (CC, $n=21$; CT, $n=41$; TT, $n=14$ ); and rs6935076 (CC, $n=30$; CT, $n=39$; TT, $n=7$ ). Age, sex, handedness, and total white matter volume were used as covariates, and the interaction of SNP, as the main factor, with age and sex was also added. This part of the analysis was repeated in the same way as the analysis previously published (Darki et al., 2012), but this time considering all three time points of the longitudinal data. We aimed to assess whether the effect of the previously published SNPs remains significant when adding the image data from the third time point. The exploratory analysis was performed on the cluster level with nonstationary cluster extent correction at $p=0.05$ (Hayasaka et al., 2004) to find the main effect of SNPs. We then corrected for multiple comparisons of three SNPs and set the threshold of significance at $p=0.016$ (Bonferroni correction of three tests). The significant regions were then saved as regions of interest (ROIs) and their overlapping area was used as a seed region for white matter tractography.

\section{Diffusion tensor imaging and fiber tracking}

Diffusion tensor imaging (DTI) with a field of view of $230 \times 230 \mathrm{~mm}^{2}$, a $128 \times 128$ matrix size, 40 slices, $2.5 \mathrm{~mm}$ slice thickness, and a b value of $1000 \mathrm{~s} / \mathrm{mm}^{2}$, and was performed in 64 gradient directions with one b0 image collected in the beginning. Eddy current and head motions were corrected with affine registration to the reference volume (b0 image) using FSL software. The diffusion tensor parameters were then estimated, and subsequently the DTI and fractional anisotropy (FA) data were constructed. Nonlinear registration was performed using TractBased Spatial Statistics (TBSS) version 1.2 (Smith et al., 2006), in FSL (Smith et al., 2004) to align all FA images to the mean FA image. TBSS back projection was used to map the significant ROI to the FA image of all individuals. Deterministic fiber tracking was then applied by ExploreDTI version 4.7.3 (Leemans et al., 2009), with $1 \mathrm{~mm}$ step size, considering an FA threshold of 0.15 and an angular difference of $30^{\circ}$, to find the white matter fibers passing through the significant ROI on individual DTI space. The traced white matter pathways of all individuals were then transformed to the mean FA template using the TBSS method for 
A
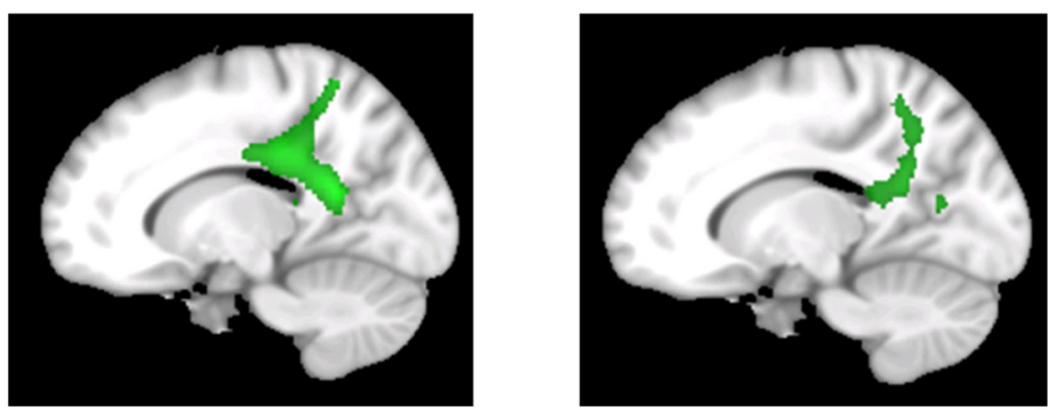

B
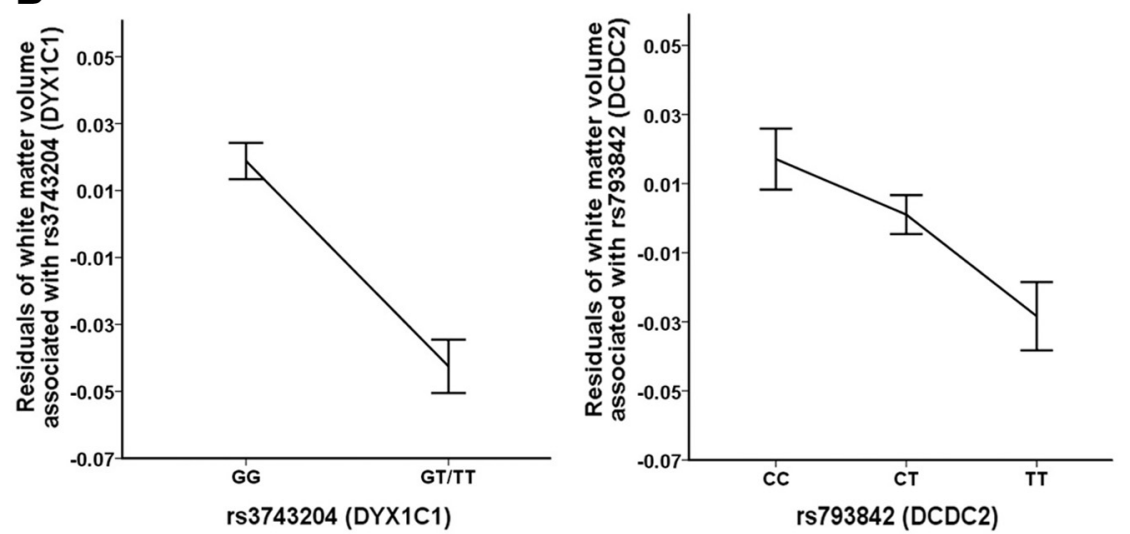
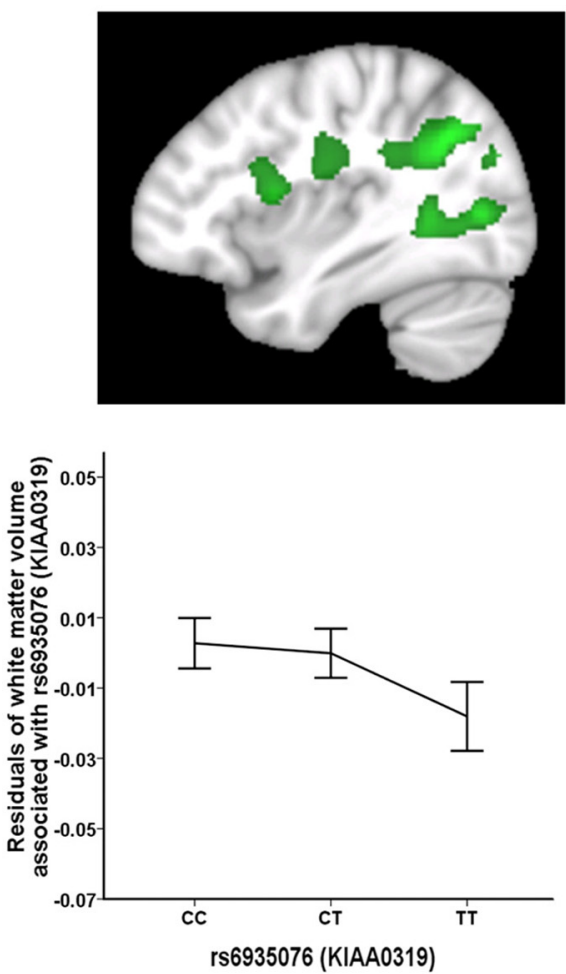

Figure 1. Main effect of three SNPs from the DYX1C1,DCDC2, and KIAA0319 genes on white matter structure. $A$, White matter clusters showing significant association between SNPs and white matter volume in sagittal sections. $\boldsymbol{B}$, Distribution of residuals of mean white matter volume in each significant region across different genotypes after correction for age, sex, and handedness. Error bars indicate \pm 1 SEM.

non-FA images in which the corresponding nonlinear transformation matrices for FA images was used to register the traced white matter pathways to template. The aligned white matter pathways were then binarized and averaged across all subjects. The averaged map of white matter pathways was then overlapped with the Harvard-Oxford cortical structural atlas to find the cortical regions connected by white matter pathways.

\section{Cortical thickness measurement}

The cortical thickness of the structural images was estimated using an automatic longitudinal stream in Freesurfer (Reuter et al., 2012) by constructing models for the boundary between gray and white matter. First, a within-subject template was created for each subject using inverse consistent registration of the T1-weighted images (Reuter et al., 2010; Reuter and Fischl, 2011). Then, several processing steps (Dale et al., 1999; Fischl and Dale, 2000), including skull removal, template transformation, and atlas registration, were performed. Images were later segmented to white matter, gray matter, and pia, based on intensity and neighborhood voxel restrictions. The distance between the white matter and the pia was computed as the thickness at each location of cortex.

To investigate our main hypothesis regarding the effect of the SNPs on cortical thickness, we first identified the cortical regions connected by white matter pathways and then we extracted their cortical thickness using the workflow described in http://surfer.nmr.mgh.harvard.edu/ fswiki/VolumeRoiCortical Thickness.

\section{Statistical analyses}

SNP genotypes and cortical thickness. To assess the effect of the SNPs on the cortical thickness of the corresponding regions, the cortical thickness of the particular ROIs was analyzed using a mixed linear model in SPSS version 21.0. The model was set for three repeated measures, and the "unstructured" type was chosen for repeated covariance. The measures of cortical thickness were entered separately as dependent variables, and the SNP genotypes were set as a factor. Age, sex, and their interactions by the SNPs, as well as handedness were entered as covariates. The main effect of the SNPs on the thickness of the cortex was tested for each ROI separately.
SNP genotypes and reading ability. The association of all three SNPs with reading scores was assessed using a mixed linear model considering three repeated measures of reading ability. The reading scores were entered as dependent variables, and the SNP genotypes were set as a factor. Age, sex, and handedness were considered as covariates. The main effect of the SNPs on the reading ability was assessed for each SNP separately. We later entered the SNP interaction by age and sex as covariates to assess for interaction possibility in the model.

Brain structure and behavior measures. The white matter volume in the SNP-associated regions as well as the thickness of the cortical areas were set separately as covariates of interest in the mixed linear model and were tested for a significant relationship to reading ability, including all three repeated measures (sex and handedness were covariates). Next, we entered age as a covariate to find the brain-behavior relationships after the effect of covariates were removed.

In another set of analyses, we assessed which brain measures can predict future reading ability. Round 1 and 2 brain measures were set as covariates, and they were analyzed to predict round 2 and 3 reading scores using a mixed linear model considering two repeated measures with sex and handedness as covariates. The model was then corrected for the effect of either age or reading at baseline to see which relationship would stay significant age independently.

\section{Results}

\section{Genetic associations to white matter volume}

In the assessment of the association of three dyslexia-related SNPs, rs793842 (DCDC2), rs6935076 (KIAA0319), and rs3743204 (DYX1C1), on white matter volume now including all three rounds of imaging of the longitudinal data, we found the same significant association with white matter volume for these SNPs, as already reported based on data from the first two time points (Darki et al., 2012). Figure $1 A$ shows the clusters found to be significant for the association of each SNP. The clusters associated with these SNPs overlapped mainly with superior longitudi- 
Table 1. Coordinates for the effect of SNPs on white matter

\begin{tabular}{|c|c|c|c|c|c|c|c|}
\hline \multirow[b]{3}{*}{ SNP } & \multirow[b]{3}{*}{ Gene } & \multirow{3}{*}{$\begin{array}{l}\text { FDR-corrected } \\
\text { cluster-level } p \\
\text { value }\end{array}$} & \multirow{3}{*}{$\begin{array}{l}\text { Cluster } \\
\text { size }\end{array}$} & \multicolumn{4}{|c|}{ Peak voxel } \\
\hline & & & & \multirow[b]{2}{*}{ z-score } & \multicolumn{3}{|c|}{ MNI coordinates } \\
\hline & & & & & $x$ & $y$ & $z$ \\
\hline rs3743204 & DYX1C1 & $1.28 \times 10^{-10}$ & 9804 & 4.11 & -16 & -54 & 18 \\
\hline rs793842 & $D C D C 2$ & $8.19 \times 10^{-5}$ & 3353 & 4.24 & -28 & -70 & 33 \\
\hline \multirow[t]{2}{*}{ rs6935076 } & KIAA0319 & $3.33 \times 10^{-10}$ & 8195 & 5.32 & -34 & -58 & 31 \\
\hline & & $3.32 \times 10^{-10}$ & 8285 & 4.01 & 36 & -28 & 37 \\
\hline
\end{tabular}

nal fasciculus and the posterior part of corpus callosum based, on the Johns Hopkins probabilistic atlas. The rs6935076 and rs3743204 clusters were bilateral, while the significant region associated with rs793842 was located only in the left hemisphere. The peak MNI coordinates, the size of the clusters, and the false discovery rate (FDR)-corrected $p$ values at cluster level are listed in Table 1. All three significant regions $\left(p<8.19 \times 10^{-5}\right)$ survived a more restricted significant threshold at multiplecomparison correction [e.g., correction for 13 SNPs (Darki et al., 2012), $p<0.0038$ ] and were overlapped in left temporoparietal area (Fig. 2A) in the same location found earlier (Darki et al., 2012). Figure $1 B$ illustrates the residual distribution of the mean white matter volume in each significant region for the related genotypes after correction for age, sex, and handedness.

\section{Fiber tracking}

An overlapping region of all three clusters was found in the left temporoparietal area (Fig. 2A) and was used as the seed region for fiber tracking. Using streamline fiber tracking, the tracts passed through this ROI were traced on all individuals DTI space separately, and then binarized and averaged across all subjects. Fiber tracking on one subject as well as the group-averaged map of the tracts across all individuals are shown in Figure 2, $B$ and $C$, respectively. Figure $2 D$ shows the white matter pathways reached to cortex after $10 \%$ thresholding. This was done to remove the uncertain voxels with the probability of having fibers in $<10 \%$ of the subjects. The averaged map of white matter pathways was then overlapped with the Harvard-Oxford cortical structural atlas and subsequently labeled with different colors (Fig. 2E). We found the white matter pathways; passed through the SNPassociated region; and connected to the left MTG, SMG, and AG, as well as to the bilateral LOC, superior parietal lobules, precuneus, and cingulate gyrus.

\section{rs793842 (DCDC2) associated with cortical thickness}

The main effects of the three SNPs on the thickness of cortical areas were assessed for the left lateral regions identified by the tract tracing (Fig. 2D) as well as their homologous areas in right hemisphere. The only significant association was between rs793842 $(D C D C 2)$ and the left lateral cortical region $\left(F_{(2,83.99)}=\right.$ 9.39, $p=2.09 \times 10^{-4}$, partial $\left.\eta^{2}=0.140\right)$. There was a trend for this SNP also for the right hemisphere $(p=0.037)$, but it did not survive the correction for multiple comparisons of six tests $\left(p_{\text {corrected }}<0.008\right)$. Next, to anatomically localize the associated regions in the left hemisphere, we tested the association of rs793842 with the thickness of each of the five segmented cortical areas (Fig. 2E). We found significant associations (Fig. $3 A$ ) between rs793842 (DCDC2) and the cortical thickness of left SMG $\left(F_{(2,86.96)}=5.05, p=2.68 \times 10^{-4}\right.$, partial $\left.\eta^{2}=0.152\right)$, left AG $\left(F_{(2,88.78)}=5.12, p=7.87 \times 10^{-3}\right.$, partial $\left.\eta^{2}=0.112\right)$, and left $\operatorname{LOC}\left(F_{(2,84.21)}=11.96, p=2.70 \times 10^{-5}\right.$, partial $\left.\eta^{2}=0.165\right)$. The cortex was significantly thicker for T-allele carriers, who also had lower white matter volume (Fig. $1 B$ ). There was also a significant interaction (Fig. 3B) between rs793842 and age on the thickness of left $\operatorname{SMG}\left(F_{(2,114.78)}=7.61, p=7.88 \times 10^{-4}\right)$ and left LOC $\left(F_{(2,110.38)}=7.77, p=6.94 \times 10^{-4}\right)$. (The mixed linear model used here did not provide the effect size or the partial $\eta$ squared. The partial $\eta^{2}$ values reported above are therefore the effect sizes from the analyses performed on time point 1 only.)

\section{Rs793842 (DCDC2) associated with reading ability}

Rs793842 (DCDC2) was the only SNP that showed significant association with reading comprehension scores $\left(F_{(2,50.02)}=4.66\right.$, $p=0.014$ ) with lower reading scores for T-allele carriers who had significantly lower white matter volume in the left temporoparietal area, and thicker cortex in the left SMG, AG, and LOC. The SNP interaction by age was not significant. No genetic association was found for a test of single-word reading, the word chain test $(p=0.608)$.

\section{Brain measures correlated with reading ability}

The reading comprehension scores were positively correlated with white matter volume in all three white matter regions $(p<$ $\left.5.00 \times 10^{-5}\right)$, also after correction for age $(p<0.001)$. Reading comprehension scores were also associated with cortical thickness in parietal regions, including left $\operatorname{SMG}\left(F_{(1,128.28)}=8.45, p=\right.$ $\left.4.32 \times 10^{-3}\right)$, right $\operatorname{SMG}\left(F_{(1,152.68)}=16.14, p=9.2 \times 10^{-5}\right)$, left $\operatorname{AG}\left(F_{(1,137.73)}=8.59, p=3.95 \times 10^{-3}\right)$, right AG $\left(F_{(1,144.97)}=\right.$ $\left.21.72, p=7.0 \times 10^{-6}\right)$, as well as the left and right $\operatorname{LOC}\left(F_{(1,111.81)}\right.$ $=7.51, p=7.15 \times 10^{-3}$; and $F_{(1,130.28)}=20.41, p=1.4 \times 10^{-5}$, respectively). In contrast to the white matter associations, the gray matter correlations did not remain significant when age was included as a covariate.

The word chain scores were associated with the white matter volumes $\left(p<10^{-6}\right)$ as well as the cortical measures in all three bilateral regions ( $p<0.036$ for MTG, $p<0.001$ for SMG, $p<$ $1.64 \times 10^{-4}$ for AG, and $p<1.0 \times 10^{-5}$ for LOC). The cortical measures did not remain significant after entering age as a covariate, but the relationships between white matter volumes and word chain scores did remain significant $(p<0.010)$.

\section{White matter volume predicted reading ability 2 years later}

The white matter volumes in the SNP-associated regions were the only brain measures that significantly predicted future reading comprehension $\left(p<4.60 \times 10^{-5}\right)$ and word chain scores $(p<$ $0.003)$. The volumes of white matter remained a significant predictor for reading comprehension 2 years later, even after correcting for age $(p<0.001)$ or reading $(p<0.041)$ at baseline.

To quantify the amount of information gained from genetic markers and brain measures compared with information gained from knowing the baseline reading comprehension score in predicting future reading ability, we compared the following two models: Model 1: Reading $2=\beta_{1} \times$ age $+\beta_{2} \times$ sex $+\beta_{3} \times$ handedness $+\beta_{4} \times$ Reading1, $r^{2}=0.617(r=0.785)$; Model 2: Reading $2=\beta_{1} \times$ age $+\beta_{2} \times$ sex $+\beta_{3} \times$ handedness $+\beta_{4} \times$ gene $+\beta_{5} \times$ white matter $+\beta_{6} \times$ cortical thickness, $r^{2}=0.613$ $(r=0.783)$. The results show that genetic information and brain measures at baseline $\left(r^{2}=0.613\right)$ are approximately as informative as knowing the baseline reading ability $\left(r^{2}=0.617\right)$ in predicting future reading comprehension.

In another analysis, we aimed to assess how much of the variance in reading scores can be explained by the brain measures. Using three different models, we showed that reading at baseline explained $8.4 \%$ more variance than the model predicted by age, sex, and handedness $\left(r^{2}=0.533\right)$. Adding genetic and structural 
A

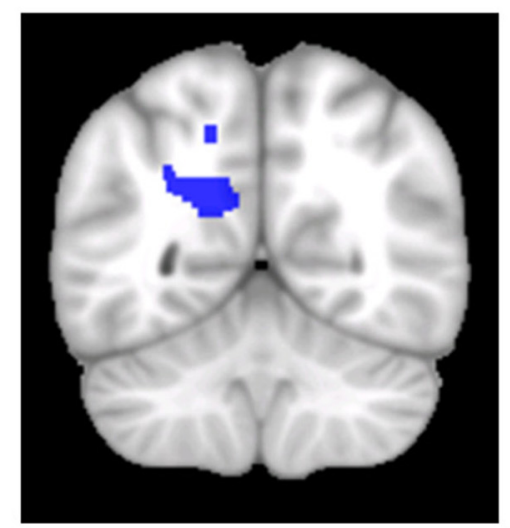

D

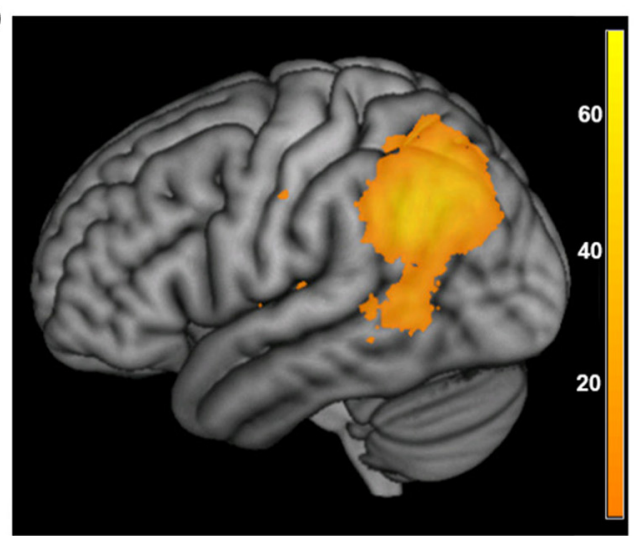

B

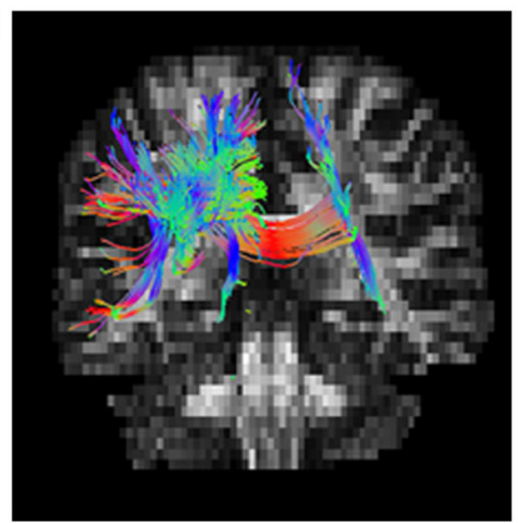

C

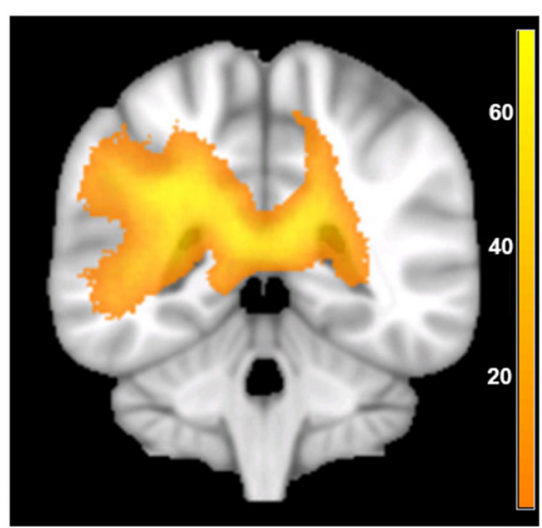

E

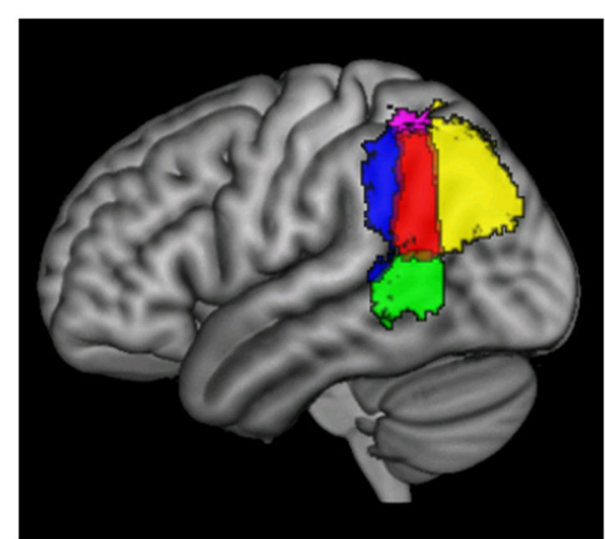

Figure 2. A, Overlap region between the significant white matter areas associated with the three dyslexia-related SNPs: rs3743204 (DYX1C1), rs793842 (DCDC2), and rs6935076 (KIAA0319). B, Example of fiber tracking of one individual (red, green, and blue fibers show left-right, anterior-posterior, and inferior-superior directions, respectively). C, Probability map of traced fibers across all individuals. D, The cortical regions most consistently connected are the middle temporal gyrus, supramarginal and angular gyri, as well as the lateral occipital cortex. The color bars correspond to the number of subjects with available white matter pathways. E, Overlapped white matter pathways with Harvard-Oxford cortical structural atlas are labeled with different colors; red for left angular gyrus, blue for left supramarginal gyrus, green for left middle temporal cortex, yellow for lateral occipital parietal cortex, and purple for superior parietal cortex.

A

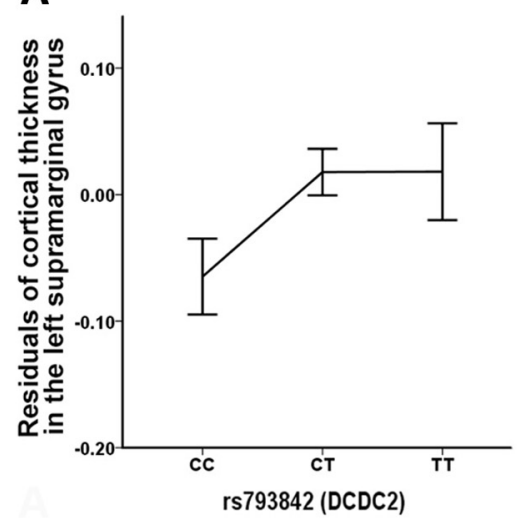

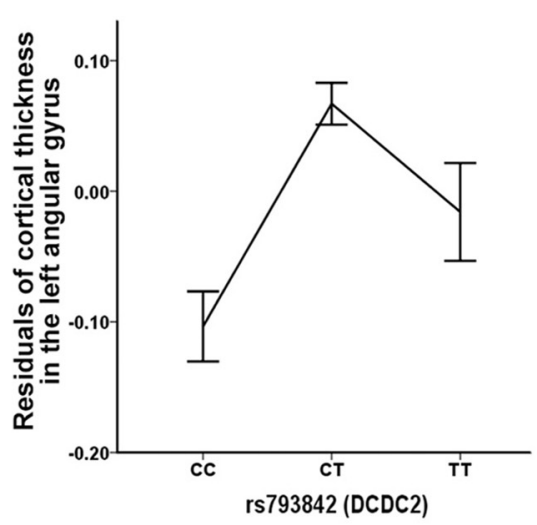

B

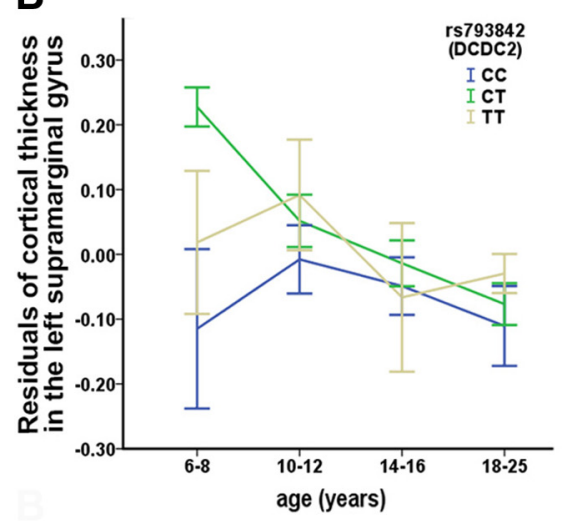

Figure 3. A, Cortical thickness of left supramarginal and angular gyri across rs793842 (DCDC2) genotypes, after correction for age, sex, and handedness. All three time points are collapsed together. $\boldsymbol{B}$, rs 793842 interaction by age for the residuals from the mean cortical thickness of left supramarginal gyrus across four different age groups after correction for sex and handedness. Error bars indicate \pm 1 SEM.

information explained another 5.9\% of unique variance about future reading comprehension.

White matter volume and cortical thickness

The white matter volume of left temporoparietal pathways negatively correlated with the cortical thickness of left AG $(p=0.004)$, SMG $(p=0.048)$, and MTG $(p=0.039)$ after correcting for the effect of sex and handedness. We did not correct for the effect of age to keep the developmental aspect of brain maturation. In another analysis, we corrected for the effect of age to see whether the link between white matter and gray matter structures are age dependent. After correcting for age, the correlation was not significant. The associations of $D C D C 2$ polymorphism with white matter volume and cortical thickness were also significant after the effect of age was removed. This suggests that the genetic associations are not de- 
pendent on the developmental relationship between brain white and gray matter measures, and that they are related to the interindividual differences.

\section{Discussion}

Here we expanded our previous analysis of the associations of three dyslexia candidate genes with brain structural measures and found that variation in DCDC2 (rs793842) affected the cortical thickness in left SMG and AG. By including three rounds of the longitudinal imaging data, we replicated our previous findings of the effect of all three SNPs (rs3743204 of DYX1C1, rs793842 of $D C D C 2$, and rs6935076 of KIAA0319) on white matter volume in left temporoparietal region (Darki et al., 2012). Both white and gray matter structures were associated with reading ability.

The white matter pathways passing through the overlapping area of the SNP-associated regions connected to the left SMG, AG, posterior MTG, and the bilateral LOC. The parietal and temporal cortical areas have been reported to be hypoactive in dyslexic subjects (Paulesu et al., 2001; McCandliss et al., 2003; Richlan et al., 2011; Richlan, 2012). Moreover, these regions showed volumetric differences in late literates relative to illiterates (Carreiras et al., 2009). The role of these cortical regions in language comprehension and semantic processing has also been established in several functional neuroimaging studies (Chertkow et al., 1997; Binder et al., 2009; Turken and Dronkers, 2011; Noonan et al., 2013).

Based on the temporoparietal white matter region, our fiber tracking was restricted to temporoparietal pathways, and they did not terminate at occipitotemporal cortical regions, which were reported to be structurally different in dyslexic individuals compared with normal control subjects (Kronbichler et al., 2008; Altarelli et al., 2013). We found connections to the LOC with the fibers extending from the posterior part of corpus callosum. LOC has been previously associated with functional and structural abnormalities in dyslexia (Pernet et al., 2009; Danelli et al., 2013). The white matter volume in the posterior part of the corpus callosum and cingulum, with the connection to the parietal, occipital, and temporal lobes, has also been associated with the other dyslexia candidate locus, MRPL19/C2ORF3 (Scerri et al., 2012), suggesting that this locus is associated with visual perception and possibly general cognitive abilities such as recognition and imagination (Danelli et al., 2013).

In the present study, the white matter volume in the SNPassociated regions as well as the cortical thickness of the parietal ROIs were significantly correlated with reading comprehension and word chain scores. This is consistent with previously published studies, which have assessed the associations between reading and white and gray matter structures (Klingberg et al., 2000; Nagy et al., 2004; Deutsch et al., 2005; Ben-Shachar et al., 2007; Blackmon et al., 2010; Welcome et al., 2011; Vandermosten et al., 2012; Wandell and Yeatman, 2013). Here, we also showed that white matter volume in the left temporoparietal tract predicted future reading ability. This emphasizes the role of white matter in driving cognitive development in children, as was previously shown for working memory (Darki and Klingberg, 2014; Ullman et al., 2014).

rs793842 within the $D C D C 2$ gene was also significantly associated with reading ability, with lower reading scores for T-allele carriers. We did not find this association in our previous study (Darki et al., 2012) where we had two rounds of the longitudinal data. T-allele carriers had significantly lower white matter volume in left temporoparietal area, and thicker cortex in left SMG, $A G$, and LOC. Previously, the genetic markers of $D C D C 2$,
KIAA0319, and DYX1C1 genes have been associated with variations in general reading ability (Luciano et al., 2007; Bates et al., 2010; Lind et al., 2010). To our knowledge, rs793842 from DCDC2 has not previously been associated with dyslexia, but it is in linkage disequilibrium with previously associated markers.

The genomic distance between DCDC2 and KIAA0319 is only $\sim 130 \mathrm{~kb}$; however, this interval is relatively rich in recombinations, and thus there is no linkage disequilibrium between the markers for both genes (Schumacher et al., 2006). Thus, any associations detected are likely to be specific for the gene implicated and not reflect a genetic effect of the other gene. The DCDC2 SNP rs793842, which showed association with cortical thickness, happens to be highly informative, with a minor allele frequency of 0.47 , which may yield optimal power for detecting associations, given that the functional haplotype covaries with this marker. Because of the more limited power for the other polymorphisms with lower frequencies, we cannot exclude the effects that the other gene might have on cortical thickness.

All three dyslexia susceptibility genes studied in this article have been associated with dyslexia (Paracchini et al., 2008; Couto et al., 2010; Newbury et al., 2011; Scerri et al., 2011; Venkatesh et al., 2013), neuronal migration (Wang et al., 2006; Gabel et al., 2010; Peschansky et al., 2010; Szalkowski et al., 2012), and ciliary function (Massinen et al., 2011; Chandrasekar et al., 2013) in developing neocortex. Another study (Rosen et al., 2007) reported neocortical and hippocampal malformations in Dyx1c1 knock-down rat brains. Similar to Dyx1c1 and Kiaa0319, the knock-down expression of $D c d c 2$ in rats disturbed the migration of neuronal precursors (Meng et al., 2005; Adler et al., 2013). Furthermore, it has been shown that the expression of $D C D C 2$ regulates the cilia length and signaling in primary rat hippocampal neurons, suggesting that $D C D C 2$ affects the structure and function of primary cilia (Massinen et al., 2011). The essential role of the other dyslexia candidate gene, DYX1C1, for cilia growth and motility in zebrafish has also been reported (Chandrasekar et al., 2013). Interestingly, the proteins produced by $D Y X 1 C 1$ and $D C D C 2$ form protein-protein complexes in a neuroblastoma cell line, suggesting that they relate to interactions at the cellular level, perhaps in cilia function (Tammimies et al., 2013).

Besides the animal models, neuroimaging studies have tried to find the link between genetic markers in dyslexia susceptibility genes and structural and functional phenotypes in human brain. Alteration in gray matter distribution has been related to a $2.4 \mathrm{~kb}$ deletion within $D C D C 2$ with higher gray matter volume in the superior and middle temporal gyri, the occipitoparietal and intraparietal areas, and the inferior and middle frontal gyri for the heterozygous healthy subjects (Meda et al., 2008). DCDC2 has also been associated with brain activation during phonological processing tasks in the superior anterior and posterior cingulate gyrus, and the left inferior frontal gyrus (Pinel et al., 2012). These studies suggest a wider cortical association with $D C D C 2$, not only a link to parietal and temporal cortex as in the present study.

While the white matter pathways studied here were correlated with the thickness of the anatomically connected cortical areas during development, they did not reveal any significant correlation between each other after the effect of age was removed. This suggests that $D C D C 2$ has an independent effect on white matter structure and cortical thickness, and that the relationship between these brain measures has not driven the genetic associations.

In summary, we attempted to find the link between dyslexia genes, gray matter structure, and reading ability. Knowing the 
role of these genes (DCDC2, KIAA0319, and DYX1C1) in neuronal migration and ciliary function as well as considering the association of these genes with variations in general reading ability (Luciano et al., 2007; Bates et al., 2010; Lind et al., 2010), we assessed whether these genetically coded molecular and neuronal mechanisms influence the brain changes, and subsequently behavior. The findings also suggest that neuroimaging can provide intermediate phenotypes as a bridge between genetic markers and behavior outcome.

\section{References}

Adler WT, Platt MP, Mehlhorn AJ, Haight JL, Currier TA, Etchegaray MA, Galaburda AM, Rosen GD (2013) Position of neocortical neurons transfected at different gestational ages with shRNA targeted against candidate dyslexia susceptibility genes. PloS One 8:e65179. CrossRef Medline

Altarelli I, Monzalvo K, Iannuzzi S, Fluss J, Billard C, Ramus F, DehaeneLambertz G (2013) A functionally guided approach to the morphometry of occipitotemporal regions in developmental dyslexia: evidence for differential effects in boys and girls. J Neurosci 33:11296-11301. CrossRef Medline

Ashburner J (2007) A fast diffeomorphic image registration algorithm. Neuroimage 38:95-113. CrossRef Medline

Bates TC, Lind PA, Luciano M, Montgomery GW, Martin NG, Wright MJ (2010) Dyslexia and DYX1C1: deficits in reading and spelling associated with a missense mutation. Mol Psychiatry 15:1190-1196. CrossRef Medline

Beaulieu C, Plewes C, Paulson LA, Roy D, Snook L, Concha L, Phillips L (2005) Imaging brain connectivity in children with diverse reading ability. Neuroimage 25:1266-1271. CrossRef Medline

Ben-Shachar M, Dougherty RF, Wandell BA (2007) White matter pathways in reading. Curr Opin Neurobiol 17:258-270. CrossRef Medline

Binder JR, Desai RH, Graves WW, Conant LL (2009) Where is the semantic system? A critical review and meta-analysis of 120 functional neuroimaging studies. Cereb Cortex 19:2767-2796. CrossRef Medline

Blackmon K, Barr WB, Kuzniecky R, Dubois J, Carlson C, Quinn BT, Blumberg M, Halgren E, Hagler DJ, Mikhly M, Devinsky O, McDonald CR, Dale AM, Thesen T (2010) Phonetically irregular word pronunciation and cortical thickness in the adult brain. Neuroimage 51:1453-1458. CrossRef Medline

Bond TG, Fox CM (2003) Applying the Rasch model: fundamental measurement in the human sciences, Ed 2. Toledo, OH: University of Toledo.

Carreiras M, Seghier ML, Baquero S, Estévez A, Lozano A, Devlin JT, Price CJ (2009) An anatomical signature for literacy. Nature 461:983-986. CrossRef Medline

Chandrasekar G, Vesterlund L, Hultenby K, Tapia-Páez I, Kere J (2013) The zebrafish orthologue of the dyslexia candidate gene DYX1C1 is essential for cilia growth and function. PLoS One 8:e63123. CrossRef Medline

Chertkow H, Bub D, Deaudon C, Whitehead V (1997) On the status of object concepts in aphasia. Brain Lang 58:203-232. CrossRef Medline

Cope N, Harold D, Hill G, Moskvina V, Stevenson J, Holmans P, Owen MJ, O’Donovan MC, Williams J (2005) Strong evidence that KIAA0319 on chromosome $6 \mathrm{p}$ is a susceptibility gene for developmental dyslexia. Am J Hum Genet 76:581-591. CrossRef Medline

Cope N, Eicher JD, Meng H, Gibson CJ, Hager K, Lacadie C, Fulbright RK, Constable RT, Page GP, Gruen JR (2012) Variants in the DYX2 locus are associated with altered brain activation in reading-related brain regions in subjects with reading disability. Neuroimage 63:148-156. CrossRef Medline

Couto JM, Livne-Bar I, Huang K, Xu Z, Cate-Carter T, Feng Y, Wigg K, Humphries T, Tannock R, Kerr EN (2010) Association of reading disabilities with regions marked by acetylated H3 histones in KIAA0319. Am J Med Genet B Neuropsychiatr Genet 153:447-462. CrossRef Medline

Dale AM, Fischl B, Sereno MI (1999) Cortical surface-based analysis: I. Segmentation and surface reconstruction. Neuroimage 9:179-194. CrossRef Medline

Danelli L, Berlingeri M, Bottini G, Ferri F, Vacchi L, Sberna M, Paulesu E (2013) Neural intersections of the phonological, visual magnocellular and motor/cerebellar systems in normal readers: implications for imaging studies on dyslexia. Hum Brain Mapp 34:2669-2687. CrossRef Medline

Darki F, Klingberg T (2014) The role of fronto-parietal and fronto-striatal networks in the development of working memory: a longitudinal study. Cereb Cortex. Advance online publication. Retrieved September 22, 2014. doi:10.1093/cercor/bht352. CrossRef Medline

Darki F, Peyrard-Janvid M, Matsson H, Kere J, Klingberg T (2012) Three dyslexia susceptibility genes, DYX1C1, DCDC2, and KIAA0319, affect temporo-parietal white matter structure. Biol Psychiatry 72:671-676. CrossRef Medline

Deutsch GK, Dougherty RF, Bammer R, Siok WT, Gabrieli JD, Wandell B (2005) Children's reading performance is correlated with white matter structure measured by diffusion tensor imaging. Cortex 41:354-363. CrossRef Medline

Eicher JD, Powers NR, Miller LL, Mueller KL, Mascheretti S, Marino C, Willcutt EG, DeFries JC, Olson RK, Smith SD, Pennington BF, Tomblin JB, Ring SM, Gruen JR (2014) Characterization of the DYX2 locus on chromosome 6p22 with reading disability, language impairment, and IQ. Hum Genet 133:869-881. CrossRef Medline

Fischl B, Dale AM (2000) Measuring the thickness of the human cerebral cortex from magnetic resonance images. Proc Natl Acad Sci U S A 97: 11050-11055. CrossRef Medline

Gabel LA, Gibson CJ, Gruen JR, LoTurco JJ (2010) Progress towards a cellular neurobiology of reading disability. Neurobiol Dis 38:173-180. CrossRef Medline

Hayasaka S, Phan KL, Liberzon I, Worsley KJ, Nichols TE (2004) Nonstationary cluster-size inference with random field and permutation methods. Neuroimage 22:676-687. CrossRef Medline

Higginbotham H, Eom TY, Mariani LE, Bachleda A, Hirt J, Gukassyan V, Cusack CL, Lai C, Caspary T, Anton ES (2012) Arl13b in primary cilia regulates the migration and placement of interneurons in the developing cerebral cortex. Dev Cell 23:925-938. CrossRef Medline

Jamadar S, Powers NR, Meda SA, Gelernter J, Gruen JR, Pearlson GD (2011) Genetic influences of cortical gray matter in language-related regions in healthy controls and schizophrenia. Schizophr Res 129:141-148. CrossRef Medline

Katusic SK, Colligan RC, Barbaresi WJ, Schaid DJ, Jacobsen SJ (2001) Incidence of reading disability in a population-based birth cohort, 19761982, Rochester, Minn. Mayo Clin Proc 76:1081-1092. CrossRef Medline

Klingberg T, Hedehus M, Temple E, Salz T, Gabrieli JD, Moseley ME, Poldrack RA (2000) Microstructure of temporo-parietal white matter as a basis for reading ability: evidence from diffusion tensor magnetic resonance imaging. Neuron 25:493-500. CrossRef Medline

Kronbichler M, Wimmer H, Staffen W, Hutzler F, Mair A, Ladurner G (2008) Developmental dyslexia: gray matter abnormalities in the occipitotemporal cortex. Hum Brain Mapp 29:613-625. CrossRef Medline

Leemans A, Jeurissen B, Sijbers J, Jones D (2009) ExploreDTI: a graphical toolbox for processing, analyzing, and visualizing diffusion $\mathrm{MR}$ data. $\mathrm{Pa}-$ per presented at ISRM 17th Annual Scientific Meeting and Exhibition, Honolulu, HI, April.

Lind PA, Luciano M, Wright MJ, Montgomery GW, Martin NG, Bates TC (2010) Dyslexia and DCDC2: normal variation in reading and spelling is associated with DCDC2 polymorphisms in an Australian population sample. Eur J Hum Genet 18:668-673. CrossRef Medline

Luciano M, Lind PA, Duffy DL, Castles A, Wright MJ, Montgomery GW, Martin NG, Bates TC (2007) A haplotype spanning KIAA0319 and TTRAP is associated with normal variation in reading and spelling ability. Biol Psychiatry 62:811-817. CrossRef Medline

Massinen S, Hokkanen ME, Matsson H, Tammimies K, Tapia-Páez I, Dahlström-Heuser V, Kuja-Panula J, Burghoorn J, Jeppsson KE, Swoboda P, Peyrard-Janvid M, Toftgård R, Castrén E, Kere J (2011) Increased expression of the dyslexia candidate gene DCDC2 affects length and signaling of primary cilia in neurons. PLoS One 6:e20580. CrossRef Medline

McCandliss BD, Cohen L, Dehaene S (2003) The visual word form area: expertise for reading in the fusiform gyrus. Trends Cogn Sci 7:293-299. CrossRef Medline

Meda SA, Gelernter J, Gruen JR, Calhoun VD, Meng H, Cope NA, Pearlson GD (2008) Polymorphism of DCDC2 reveals differences in cortical morphology of healthy individuals - a preliminary voxel based morphometry study. Brain Imaging Behav 2:21-26. CrossRef Medline

Meng H, Smith SD, Hager K, Held M, Liu J, Olson RK, Pennington BF, DeFries JC, Gelernter J, O'Reilly-Pol T, Somlo S, Skudlarski P, Shaywitz SE, Shaywitz BA, Marchione K, Wang Y, Paramasivam M, LoTurco JJ, Page GP, Gruen JR (2005) DCDC2 is associated with reading disability 
and modulates neuronal development in the brain. Proc Natl Acad Sci U S A 102:17053-17058. CrossRef Medline

Nagy Z, Westerberg H, Klingberg T (2004) Maturation of white matter is associated with the development of cognitive functions during childhood. J Cogn Neurosci 16:1227-1233. CrossRef Medline

Newbury DF, Paracchini S, Scerri TS, Winchester L, Addis L, Richardson AJ, Walter J, Stein JF, Talcott JB, Monaco AP (2011) Investigation of dyslexia and SLI risk variants in reading-and language-impaired subjects. Behav Genet 41:90-104. CrossRef Medline

Niogi SN, McCandliss BD (2006) Left lateralized white matter microstructure accounts for individual differences in reading ability and disability. Neuropsychologia 44:2178-2188. CrossRef Medline

Noonan KA, Jefferies E, Visser M, Lambon Ralph MA (2013) Going beyond inferior prefrontal involvement in semantic control: evidence for the additional contribution of dorsal angular gyrus and posterior middle temporal cortex. J Cogn Neurosci 25:1824-1850. CrossRef Medline

Paracchini S, Steer CD, Buckingham LL, Morris AP, Ring S, Scerri T, Stein J, Pembrey ME, Ragoussis J, Golding J, Monaco AP (2008) Association of the KIAA0319 dyslexia susceptibility gene with reading skills in the general population. Am J Psychiatry 165:1576-1584. CrossRef Medline

Paulesu E, Démonet JF, Fazio F, McCrory E, Chanoine V, Brunswick N, Cappa SF, Cossu G, Habib M, Frith CD, Frith U (2001) Dyslexia: cultural diversity and biological unity. Science 291:2165-2167. CrossRef Medline

Pernet C, Andersson J, Paulesu E, Demonet JF (2009) When all hypotheses are right: a multifocal account of dyslexia. Hum Brain Mapp 30:22782292. CrossRef Medline

Peschansky VJ, Burbridge TJ, Volz AJ, Fiondella C, Wissner-Gross Z, Galaburda AM, Lo Turco JJ, Rosen GD (2010) The effect of variation in expression of the candidate dyslexia susceptibility gene homolog Kiaa0319 on neuronal migration and dendritic morphology in the rat. Cereb Cortex 20:884-897. CrossRef Medline

Pinel P, Fauchereau F, Moreno A, Barbot A, Lathrop M, Zelenika D, Le Bihan D, Poline JB, Bourgeron T, Dehaene S (2012) Genetic variants of FOXP2 and KIAA0319/TTRAP/THEM2 locus are associated with altered brain activation in distinct language-related regions. J Neurosci 32:817-825. CrossRef Medline

Reuter M, Fischl B (2011) Avoiding asymmetry-induced bias in longitudinal image processing. Neuroimage 57:19-21. CrossRef Medline

Reuter M, Rosas HD, Fischl B (2010) Highly accurate inverse consistent registration: a robust approach. Neuroimage 53:1181-1196. CrossRef Medline

Reuter M, Schmansky NJ, Rosas HD, Fischl B (2012) Within-subject template estimation for unbiased longitudinal image analysis. Neuroimage 61:1402-1418. CrossRef Medline

Richlan F (2012) Developmental dyslexia: dysfunction of a left hemisphere reading network. Front Hum Neurosci 6:120. CrossRef Medline

Richlan F, Kronbichler M, Wimmer H (2011) Meta-analyzing brain dysfunctions in dyslexic children and adults. Neuroimage 56:1735-1742. CrossRef Medline

Rosen GD, Bai J, Wang Y, Fiondella CG, Threlkeld SW, LoTurco JJ, Galaburda AM (2007) Disruption of neuronal migration by RNAi of Dyx1c1 results in neocortical and hippocampal malformations. Cereb Cortex 17: 2562-2572. CrossRef Medline

Scerri TS, Morris AP, Buckingham LL, Newbury DF, Miller LL, Monaco AP, Bishop DV, Paracchini S (2011) DCDC2, KIAA0319 and CMIP are associated with reading-related traits. Biol Psychiatry 70:237-245. CrossRef Medline

Scerri TS, Darki F, Newbury DF, Whitehouse AJ, Peyrard-Janvid M, Matsson $\mathrm{H}$, Ang QW, Pennell CE, Ring S, Stein J, Morris AP, Monaco AP, Kere J, Talcott JB, Klingberg T, Paracchini S. (2012) The dyslexia candidate locus on $2 \mathrm{p} 12$ is associated with general cognitive ability and white matter structure. PLoS One 7:e50321. CrossRef Medline

Schumacher J, Anthoni H, Dahdouh F, König IR, Hillmer AM, Kluck N, Manthey M, Plume E, Warnke A, Remschmidt H (2006) Strong genetic evidence of DCDC2 as a susceptibility gene for dyslexia. Am J Hum Genet 78:52-62. CrossRef Medline

Shaywitz BA, Shaywitz SE, Pugh KR, Mencl WE, Fulbright RK, Skudlarski P, Constable RT, Marchione KE, Fletcher JM, Lyon GR, Gore JC (2002)
Disruption of posterior brain systems for reading in children with developmental dyslexia. Biol Psychiatry 52:101-110. CrossRef Medline

Shaywitz BA, Shaywitz SE, Blachman BA, Pugh KR, Fulbright RK, Skudlarski P, Mencl WE, Constable RT, Holahan JM, Marchione KE, Fletcher JM, Lyon GR, Gore JC (2004) Development of left occipitotemporal systems for skilled reading in children after a phonologically-based intervention. Biol Psychiatry 55:926-933. CrossRef Medline

Shaywitz SE, Shaywitz BA, Fletcher JM, Escobar MD (1990) Prevalence of reading disability in boys and girls. JAMA 264:998-1002. CrossRef Medline

Silani G, Frith U, Demonet JF, Fazio F, Perani D, Price C, Frith CD, Paulesu E (2005) Brain abnormalities underlying altered activation in dyslexia: a voxel based morphometry study. Brain 128:2453-2461. CrossRef Medline

Smith SM, Jenkinson M, Woolrich MW, Beckmann CF, Behrens TE, Johansen-Berg H, Bannister PR, De Luca M, Drobnjak I, Flitney DE, Niazy RK, Saunders J, Vickers J, Zhang Y, De Stefano N, Brady JM, Matthews PM (2004) Advances in functional and structural MR image analysis and implementation as FSL. Neuroimage 23:S208-S219. CrossRef Medline

Smith SM, Jenkinson M, Johansen-Berg H, Rueckert D, Nichols TE, Mackay CE, Watkins KE, Ciccarelli O, Cader MZ, Matthews PM, Behrens TE (2006) Tract-based spatial statistics: voxelwise analysis of multi-subject diffusion data. Neuroimage 31:1487-1505. CrossRef Medline

Söderqvist S, McNab F, Peyrard-Janvid M, Matsson H, Humphreys K, Kere J, Klingberg T (2010) The SNAP25 gene is linked to working memory capacity and maturation of the posterior cingulate cortex during childhood. Biol Psychiatry 68:1120-1125. CrossRef Medline

Szalkowski CE, Fiondella CG, Galaburda AM, Rosen GD, Loturco JJ, Fitch RH (2012) Neocortical disruption and behavioral impairments in rats following in utero RNAi of candidate dyslexia risk gene Kiaa0319. Int J Dev Neurosci 30:293-302. CrossRef Medline

Taipale M, Kaminen N, Nopola-Hemmi J, Haltia T, Myllyluoma B, Lyytinen H, Muller K, Kaaranen M, Lindsberg PJ, Hannula-Jouppi K, Kere J (2003) A candidate gene for developmental dyslexia encodes a nuclear tetratricopeptide repeat domain protein dynamically regulated in brain. Proc Natl Acad Sci U S A 100:11553-11558. CrossRef Medline

Tammimies K, Vitezic M, Matsson H, Le Guyader S, Bürglin TR, Ohman T, Strömblad S, Daub CO, Nyman TA, Kere J, Tapia-Páez I (2013) Molecular networks of DYX1C1 gene show connection to neuronal migration genes and cytoskeletal proteins. Biol Psychiatry 73:583-590. CrossRef Medline

Turken AU, Dronkers NF (2011) The neural architecture of the language comprehension network: converging evidence from lesion and connectivity analyses. Front Syst Neurosci 5:1. CrossRef Medline

Ullman H, Almeida R, Klingberg T (2014) Structural maturation and brain activity predict future working memory capacity during childhood development. J Neurosci 34:1592-1598. CrossRef Medline

Vandermosten M, Boets B, Wouters J, Ghesquière P (2012) A qualitative and quantitative review of diffusion tensor imaging studies in reading and dyslexia. Neurosci Biobehav Rev 36:1532-1552. CrossRef Medline

Venkatesh SK, Siddaiah A, Padakannaya P, Ramachandra NB (2013) Lack of association between genetic polymorphisms in ROBO1, MRPL19/ C2ORF3 and THEM2 with developmental dyslexia. Gene 529:215-219. CrossRef Medline

Vinckenbosch E, Robichon F, Eliez S (2005) Gray matter alteration in dyslexia: converging evidence from volumetric and voxel-by-voxel MRI analyses. Neuropsychologia 43:324-331. CrossRef Medline

Wandell BA, Yeatman JD (2013) Biological development of reading circuits. Curr Opin Neurobiol 23:261-268. CrossRef Medline

Wang Y, Paramasivam M, Thomas A, Bai J, Kaminen-Ahola N, Kere J, Voskuil J, Rosen GD, Galaburda AM, Loturco JJ (2006) DYX1C1 functions in neuronal migration in developing neocortex. Neuroscience 143: 515-522. CrossRef Medline

Welcome SE, Chiarello C, Thompson PM, Sowell ER (2011) Reading skill is related to individual differences in brain structure in college students. Hum Brain Mapp 32:1194-1205. CrossRef Medline

Woodcock RW (1987) Woodcock reading mastery tests, revised. Circle Pines, MN: American Guidance Service. 